\title{
Effect of metformin on thyroid function tests in type 2 diabetic patients
}

\author{
Mohammed N. Abed \\ Department of Pharmacology and Toxicology, College of Pharmacy, University of Mosul, Mosul, Iraq \\ correspondence: greatpharmacyzooz@yahoo.com
}

Received

14.1.2014

Accepted

4.3.2014

\begin{abstract}
Background: Diabetes mellitus (DM) and thyroid disorder appears to be closely related.It has long been recognised that thyroid hormones have marked effects on glucose homeostasis, and although autoimmune thyroid disease is more prevalent in type 1 diabetes as a result of their common origin, in patients with type 2 diabetes the prevalence of hypothyroidism and hyperthyroidism is similar to that of the general population. The present study was conducted to assess the interplay between metformin treatment and thyroid function in type 2 diabetic patients.

Methods: A total of 73 diabetic patients were enrolled in this study, they were divided into two groups, the first group included 37 type 2 diabetic patients on metformin therapy, whereas the second group involved 36 type 1 diabetic patients on insulin therapy. Another group involved 35 apparently healthy volunteers were also included in the study as a control group. Blood samples were taken from the patients and controls, then the serum was analyzed for measurement of fasting serum glucose (FSG), total T3, free T3 (FT3), total T4, freeT4 FT4) and TSH using ELFA (Enzyme Linked Fluorescent Assay) technique (minividas).

Results: the results showed that there were no significant differences between T3, FT3, FT4 and TSH of the metformin group when compared to the same parameters in the control group. On the other hand FT3 and FT4 of insulin group were significantly lower than that of the control and metformin groups. Also total T4 inmetformin and insulin groups was significantly lower than that of control group, whereas the TSH of insulin group was significantly higher than that of control and metformin groups.

Conclusion:Chronic use of metformin in type 2 diabetic patients has no effects on thyroid function tests, and there was no significant correlation between glycemic control and thyroid hormones or TSH. However, TSH, T4, FT3 and FT4 in insulin group were significantly differe from control group and this may indicate the presence of subclinical hypothyroidism.
\end{abstract}

Key words: diabetes mellitus, metformin, insulin, thyroid hormons.

الخلاصة

خلفية البحث: تقييم العلاقة بين العلاج بالميتفورمين و وظيفة الغدة الدرقية في مرضى السكري من النوع الثياني..

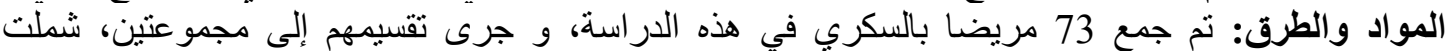

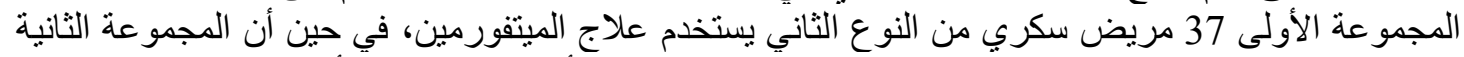

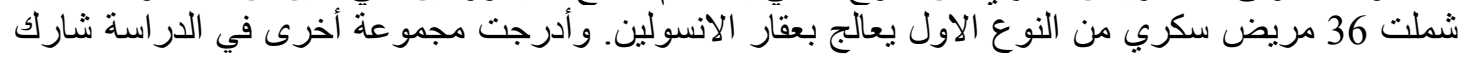

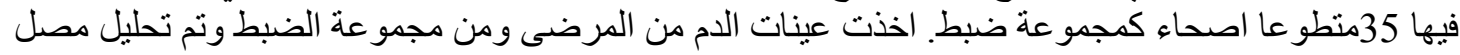
الدم لقياس سكر المصل وفحوصات وظائف الغدة الدرقية وفحص الهرمئ الثرن المحفز للغدة الدرقية باستخدام جهاز ميني فايدس النتائج: أظهرت النتائج عدم وجود فروق ذات دلالة إحصائية معنوية في هورمونات الغدة الدرقية وو الهورمون

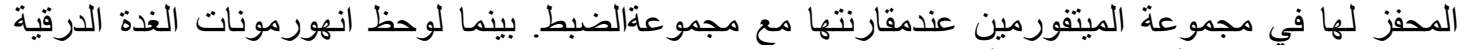

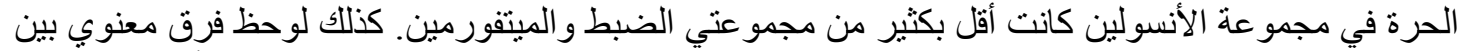

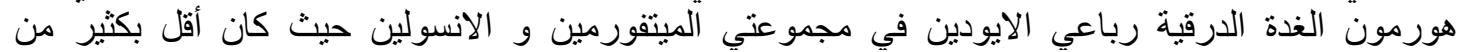
المجموعة الضابطة، في حين كانالهورمون المحفز للخدة الدرقية في في مجموعة الأنسولين أعلى بكثير من مجموعتي الضبطو الميتفورمين. 
الاستنتاج: الاستخدام المزمن للميتفورمين في مرضى السكري من النوع الثاني ليس له أي آثار في اختبارات

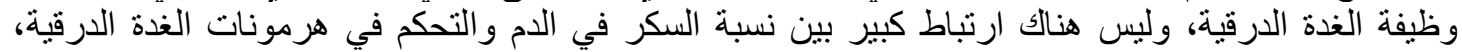

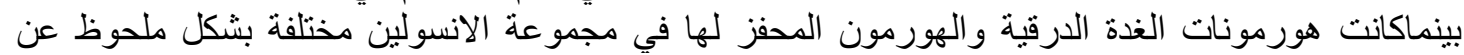

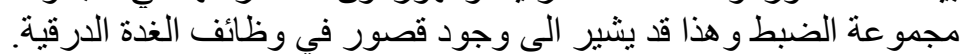

$\mathrm{D}$ iabetes mellitus (DM) and thyroid disorder appears to be closely related $^{1}$.It has long been recognised that thyroid hormones have marked effects on glucose homeostasis, and although autoimmune thyroid disease is more prevalent in type 1 diabetes as a result of their common origin, in patients with type 2 diabetes the prevalence of hypothyroidism and hyperthyroidism is similar to that of the general population ${ }^{2}$.

A recent study of all available data in patients with DM revealed a mean frequency of thyroid disease of $11 \%{ }^{3}$. The global effects of thyroid function on insulin secretion, action and glucose uptake can be explained by the action of thyroid hormon on peripheral tissue $^{(4)}$.Insulin secretion is under direct control of thyroid hormon, and in hypothyroidism, glucose-induced insulin secretion by the $\beta$-cells is reduced. Although data are more heterogeneous in hyperthyroidism, $\beta$ cell response to glucose or catecholamine stimulation appears to be increased in hyperthyroidism. This is accompanied by an increased $\beta$-cell mass. In parallel, insulin clearance is increased in thyrotoxicosis. Experimental hypothyroidism and hyperthyroidism in healthy subjects, and endogenous thyrotoxicosis or hypothyroidism, affect glucose uptake ${ }^{4,5}$.

For long period of time metformin (abiguanide oral antidiabetic compound), was used for the treatment of type 2 diabetes ${ }^{6,7}$.In recent years, metformin has become the first line therapy for patients with type 2 diabetes $^{8}$. Thus far, metformin is the only antidiabetic agent which has shown reduced mortality among overweight patients with DM in addition to reduction in macrovascular outcomes which are likely explained by its effects beyond glycemic control $^{9,10}$. Its primary action is to inhibit hepatic glucose production and glucose uptake and disposal in muscle, but it also increases the sensitivity of peripheral tissues to insulin ${ }^{11}$.

Recently it has been reported that metformin is able to interfere with thyroid hormone profile in hypothyroid patients in stable levothyroxine treatment $^{12,13,14}$. However, no data are available for untreated hypothyroid patients or for euthyroid diabetic patients. Given that both metformin treatment and hypothyroidism are frequent occurrences in diabetic patients ${ }^{15}$.

To further characterise the effect of metformin treatment on circulating thyroid function parameters, this study aimed to investigate the effect metformin treatment on the serum levels of thyroid hormones and TSH in patients with type 2 diabetes mellitus.

There are little surveys analysing the relationship between metformin and thyroid function in diabetic patients. Therefore, the aim of the present study has been to evaluate serum TSH and thyroid hormons levels in patients with type 2 diabetes, and their relationship with metformin.

\section{Materials and methods}

This study was conducted in MosulIraq during the period from 15th of 
January 2012 to the 15 th of September 2012. A total of 73 diabetic patients were enrolled in this study, they were divided into two groups, the first group included 37 type 2 diabetic patients (17 male and 20 female) on metformin therapy; their mean age was $54.41 \pm 8.15$ years whereas the second group involved 36 type 1 diabetic patients (15male and 21 female) on insulin therapy; their mean age was

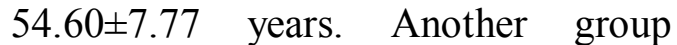
involved thirty five apparently healthy volunteers (16 male and 19 female), were also included in the study as a control group; their mean age was $53.65 \pm 6.27$ years.

The study design was case-control study and the patients were excluded if they had a history of hypertension, angina pectoris, myocardial infarction, heart failure, renal or hepatic failure or those taking hypoglycemic agents other than metformin and insulin. Pregnant women and lactating mother were also excluded from the study.

Seven milliliters of venous blood, for laboratory evaluation of biochemical parameters, were obtained from all participants after an overnight fasting (12-hours) by antecubital vein puncture. The blood was allowed to clot at room temperature and after centrifugation the serum was collected in plane tube and analyzed. Fasting serum glucose was estimated by glucose-oxidase-peroxidase spectrophotometric method, by using a kit supplied by Biocon company (Germany). Thyroid hormones; total triiodothyronine (total T3), free triiodothyronine (FT3), total thyroxine (total T4) and free thyroxine (FT4) and TSH were measured using ELFA (Enzyme Linked Fluorescent Assay) technique (minividas (biomerieux) France), by using kit supplied by Biomerieux company (France).

\section{Statistical analysis}

All values expressed as Mean \pm SD and $P$ value of $\leq 0.05$ was considered to be statistically significant. Two sample t-test and Pearson's correlation were used to compare the results of various parameters among the studied groups. Statistical analysis was done using Minitab for Windows statistical software, version 14 .

\section{Results}

Age of the participants, body mass index (BMI), and duration of treatment by metformin or insulin and gender are shown in (table 1). There were no significant differences between the studied groups regarding age and BMI.

Table 1. Demographic characteristics of the studied groups

\begin{tabular}{|c|c|c|c|}
\hline Parameters & $\begin{array}{c}\text { Control } \\
\text { group } \\
(\text { No. }=35)\end{array}$ & $\begin{array}{c}\text { Metformin } \\
\text { group } \\
(\text { No. }=37)\end{array}$ & $\begin{array}{c}\text { Insulin } \\
\text { group } \\
(\text { No. }=36)\end{array}$ \\
\hline Age (years) & $53.65 \pm 6.27$ & $54.41 \pm 8.15^{\mathrm{NS}}$ & $54.60 \pm 7.77^{\mathrm{NS}}$ \\
\hline BMI (kg/m $\left.{ }^{2}\right)$ & $27.52 \pm 1.62$ & $28.25 \pm 2.11^{\mathrm{NS}}$ & $28.77 \pm 3.29^{\mathrm{NS}}$ \\
\hline Duration of treatment (years) & $\ldots \ldots \ldots$ & $6.5 \pm 2.07$ & $7.13 \pm 2.11$ \\
\hline Gender (male/Female) & $16 / 19$ & $17 / 20$ & $15 / 21$ \\
\hline
\end{tabular}


Table 2. the FSG, total T3, FT3, total T4, FT4 and TSH for the studied groups

\begin{tabular}{|c|c|c|c|}
\hline Parameters & $\begin{array}{c}\text { Control } \\
\text { group } \\
(\text { No.=35) }\end{array}$ & $\begin{array}{c}\text { Metformin group } \\
(\text { No.=37) }\end{array}$ & $\begin{array}{c}\text { Insulin } \\
\text { group } \\
(\text { No. }=36)\end{array}$ \\
\hline FSG (mmol/l) & $4.89 \pm 0.62$ & $9.03 \pm 2.40^{\mathrm{a}}$ & $8.87 \pm 2.41^{\mathrm{a}}$ \\
\hline FT3(pmol/l) & $6.64 \pm 2.35$ & $6.92 \pm 2.55$ & $4.80 \pm 0.36^{\mathrm{ab}}$ \\
\hline FT4(pmol/l) & $15.70 \pm 2.2$ & $14.22 \pm 2.33$ & $12.25 \pm 1.45^{\mathrm{ab}}$ \\
\hline Total T3(nmol/l) & $1.69 \pm 0.26$ & $1.79 \pm 0.31$ & $1.68 \pm 0.45$ \\
\hline Total T4(nmol/l) & $112.2 \pm 10.1$ & $101.72 \pm 9.67^{\mathrm{a}}$ & $101.5 \pm 13.0^{\mathrm{a}}$ \\
\hline TSH(mIU/l) & $1.28 \pm 0.62$ & $1.64 \pm 1.62$ & $2.56 \pm 1.31^{\mathrm{a}}$ \\
\hline
\end{tabular}

$\mathrm{a}=$ significant differences $(\mathrm{P} \leq 0.05)$ as compared to the same parameters in the control group. $\quad b=$ significant differences $(P \leq 0.05)$ as compared to the same parameters in the metformin group.

Table 3. the Pearson's correlation between FSG and thyroid hormones and TSH

\begin{tabular}{|c|c|c|c|c|}
\hline \multicolumn{2}{|c|}{ Mean \pm SD(No. 63 patients) } & \multirow{2}{*}{ P value } & \\
\cline { 1 - 2 } Thyroid function tests & FSG $(\mathrm{mmol} / \mathrm{l})$ & & \\
\hline FT3(pmol/l) & $5.62 \pm 2.2$ & $8.95 \pm 2.37$ & -0.209 & 0.258 \\
\hline FT4(pmol/l) & $12.76 \pm 2.34$ & $8.95 \pm 2.37$ & -0.280 & 0.127 \\
\hline Total T3(nmol/l) & $1.76 \pm 0.42$ & $8.95 \pm 2.37$ & 0.151 & 0.418 \\
\hline Total T4(nmol/l) & $100.61 \pm 12.36$ & $8.95 \pm 2.37$ & -0.142 & 0.445 \\
\hline TSH(mIU/l) & $2.37 \pm 2.44$ & $8.95 \pm 2.37$ & -0.036 & 0.846 \\
\hline
\end{tabular}

There were non significant correlations between the FSG and all thyroid hormone parameters and TSH in diabetic patients, as shown in (table 3).

\section{Discussion}

It is important to diagnose thyroid dysfunction in diabetic patients, andthis practice should be inculcated in clinical settings withimmediate effect to nourish further understanding of thyroiddysfunction and diabetes mellitus.

To exclude the effect of diabetes on thyroid gland, the present study compared thyroid function test of metformin with that of type 1 diabetic patients on insulin therapy, also, in this study the patient and the control groups were matched regarding age and BMI.
This matching has a beneficial effect in that it excludes any effects of differences in age and BMI on the outcome of the study.

This study found that there were no effect for metformin therapy on $\mathrm{TSH}$, FT3 and FT4 values and the oral antidiabetic metformin;this finding suggest that TSH, thyroid hormons and metformin are not independently related ${ }^{16}$.Findings of this study are in line with those of Oleandri et al.study, which assessed the effects of 3-month treatment with metformin on anthropometric, metabolic and hormonal variables, including TSH and thyroid hormones. Their results showed that metformin did not modify the effect of diet on serum TSH concentrations in patients with 
obesity $^{17}$. The effects of metformin treatment on the thyroid hormone profile have been evaluated in a recent prospective study including 24 euthyroid women with polycystic ovary syndrome ${ }^{18}$. Serum levels of TSH before starting metformin therapy did not significantly change after a 4month course of metformin therapy. Similarly, there were no significant changes in serum-free T4 in this group of women with euthyroidism ${ }^{18}$. Furthermore, no TSH-lowering effect could be demonstrated in the group of patients with type 2 diabetes and integrity of the pituitary-thyroid axis.

A studies done by Vigersky et al., Cappelli et al.,and Chen et al. ${ }^{19-21}$ evaluated the thyroid hormone profile by studying the interaction between metformin and circulating thyroid function parameters in patients who were started on metformin, their results regarding thyroid hormons are consistent with the present study findings, however these studiesshowed significant fall of TSH level in euthyroid patients on levothyroxin substitution and subclinical hypothyroid patientswho did not receive levothyroxin treatment.These studies concluded that TSH lowering effect of metformin only seen in untreated hypothyroid patient and with levothyroxin replacement therapy irrespective of thyroid function test and this may explain their inconsistency with the present study finding regarding TSH level, so it is interesting that the TSH-reducing effect of metformin has been reported only in diabetic subjects with hypothyroidism, but not in patients with euthyroidism.

TSH levels in the present studywere significantly elevated in insulin group when compared to the control and metformin group. High TSH level is clearly suggestive of the hypothyroid state with lower levels of FT3 and FT4 that is commonly associated with type
1 diabetes mellitus. There are a number of reports on the TSH levels in type 1 diabetes mellitus and their results are in agreement with the present study because many of them have recorded elevated TSH levels ${ }^{22-25}$.

The present study also showed non significant correlation between fasting serum glucose levels and parameters of thyroid function test. This may suggests that absence or minimal role of blood sugar concentration in thyroid dysfunction and further studies with glycated hemoglobin may be necessary to find out the role of glycemic status in causing thyroid dysfunction ${ }^{29,30}$. In conclusion, this studydid not found any effect of metformin therapy on $\mathrm{TSH}$, thyroid hormonslevels in type 2 diabetic patients.However, TSH, FT3 and FT4 were significantly different from control group in insulin group and this may indicate the presence of subclinical hypothyroidism. In such patients, annual screening of thyroid function may be required in particular in endemic area with goiter because their FSG levels do not predict the risk. Further prospective studies in large samples of euthyroidpatients with diabetes are needed to clarify the effect of differentdoses and duration of treatment with metformin onthyroid economy.

\section{References}

1. Perros P, McCrimmon RJ, Shaw G. Frequency of thyroid dysfunction in diabetic patients value of annual screening. Diabetic Med 1995;12: 622-627.

2. Brenta G. Diabetes and thyroid disorders. British J Dia Vascul Dis 2010;10:172-177.

3. Kadiyala R, Peter R, Okosieme OE. Thyroid dysfunction in patients with diabetes: clinical implications and screening strategies. Int $\mathrm{J}$ Clin Pract 2010;64:1130-1139. 
4. Mitrou P, Boutati E, Lambadiari V. Insulin resistance in hyperthyroidism: the role of IL6 and TNF alpha. Eur J Endocrinol 2010; 162:121-126.

5. Stanická, S, Vondra, K., Pelikánová, $\mathrm{T}$. Insulin sensitivity and counterregulatory hormones in hypothyroidism and during thyroid hormone replacement therapy. Clin Chem Lab Med 2005;43:715-720.

6. Bloomgarden ZT. Approaches to treatment of type 2 diabetes. Diabetes Care 2008;31:1697-1703

7. Schwartz S, Fonseca V, Berner B et al. Efficacy, tolerability, and safety of a novel once-daily extended - release metformin in patients with type 2 diabetes. Diabetes Care 2006;29:759764

8. Beatriz L, Rojas A, Gomes MB. Metformin: an old but still the best treatment fortype 2 diabetes. Diabetology Metab Synd 2013; 5:6:115

9. Sathyapalan T, Manuchehri AM, Rigby AS. Subclinical hypothyroidism is associated with reduced all-cause mortality in patients with type 2 diabetes. Diabetes Care 2010;33: e37.

10. Genuth S. The UKPDS and its global impact. Diabetic Med 2008; 25(Suppl 2):57-62.

11. Bailey $\mathrm{CJ}$ and Turner RC. Metformin. N Engl J Med 1996; 334:574579.

12. Cappelli C, Rotondi M, Pirola I, et al. TSH-lowering effect of metformin in type 2 diabetic patients. Diabetes Care 2009; 32: 1589-1590.

13. Vigersky RA, Filmore-Nassar A, Glass AR. Thyrotropin suppression by metformin. J Clin Endocrinol Metab 2006;91: 225-227

14. Isidro ML, Penín MA, Nemina R, et al. Metformin reduces thyrotropin levels in obese, diabetic women with primary hypothyroidism on thyroxine replacement therapy. Endocrine 2007;32:79-82
15. Chubb SA, Davis WA, Inman Z, et al. Prevalence and progression of subclinical hypothyroidism in women with type 2 diabetes: the Fremantle Diabetes Study. Clin Endocrinol (Oxf) 2005;62:480-486.

16. Juan J. Diez, Iglesias $P$. Relationship between serum thyrotropin concentrations and metformin therapy in euthyroid patients with type 2 diabetes. Clin Endocrinol 2013; 78:505-511

17. Oleandri SE, Maccario M, Rossetto R. Threemonth treatment with metformin or dexfenfluramine does not modify the effects of diet on anthropometric and endocrinemetabolic parameters in abdominal obesity. J Endocrin Invest 1999; 22: 137-140.

18. Rotondi M, Cappelli C, Magri F. Thyroidal effect of metformin treatment in patients with polycystic ovary syndrome. Clinical Endocrinology 2011;75: 378-381.

19. Vigersky RA, Filmore-Nassar A, Glass AR. Thyrotropin suppression by metformin. Journal of Clinical Endocrinology \& Metabolism 2006; vol 91(1): 225-227.

20. Cappelli C, Rotondi M, Pirola I, et al. Thyreotropin levels in diabetic patients on metformin treatment. Eur J Endocrino 2012; vol 167(2):261-265.

21. Chen $\mathrm{G}, \mathrm{Xu} \mathrm{S}$, Renko $\mathrm{K}$, et al. Metformin inhibits growth of thyroid carcinoma cells, suppresses selfrenewal of derived cancer stem cells, and potentiates the effect of chemotherapeutic agents. J Clin Endocrinol Met 2012; vol 97: E510E520.

22. Gray RS, Borsey DQ, Seth J et al. Prevalence of subclinical thyroid failure in insulin-dependent diabetes mellitus. J Clin Endocrinol Metab 1980; 50 (6): 1034-1037.

23. Muralidhara $\mathrm{KC}$, Vibha $\mathrm{C}$, Manohar CS, et al. Thyroid dysfunction in 
type 1 diabetes. Int J Basic Med Sc 2013;3 (6): 37-40.

disease in children with IDDM. Diabetes Care 1990; 13: 801-803.

25. Darendeliler FF, Kadioglu A, Firdevs B et al. Thyroid ultrasound in IDDM. Journal of Pediatric Endocrinology 1994; 7: 33-37.

26. Proces S, Delgrange E, VanderBorght TV et al. Minor alterations in thyroid function tests associated with diabetes mellitus and obesity in outpatients without known thyroid illness. Acta Clin Belg 2001; 56 (2):86-90.

27. Schlienger JL, Anceau A, Chabrier $G$ et al.. Effect of diabetic control on the level of circulating thyroid hormones. Diabetologia, 1982;22:486488.
24. McKenna MJ, Herskowitz R, Wolfsdorf JI. Screening for thyroid

28.Nadez-Real JF, Pez-Bermejo A, Castro A, et al. Thyroid function is intrinsically linked to insulin sensitivity and endothelium-dependent vasodilation in healthy euthyroid subjects. J Clin Endocrinol Metab 2006; 92(9):3337-3343.

29. Ikeda $T$, Ito $Y$, Murakami I, et al. Effect of glibenclamide on thyroid hormone metabolism in rats. Horm Metab Res1986; 18 (8):517-520.

30. Swamy RM, Kumar N, Srinivasa $\mathrm{K}$, et al. Evaluation of hypothyroidism as a complication in type IIdiabetes mellitus. Biomedical Research 2012; 23(2):170-172. 